\title{
REGIONAL PLAN AND PROGRAM LINKED TO EU POLICY FOR CITY LOGISTICS: THE CASE OF CALABRIA REGION, ITALY
}

\author{
TOMMASO CALABRÒ, MASSIMILIANO COZZA D’ONOFRIO, \\ GIUSEPPE IIRITANO \& MARIA ROSARIA TRECOZZI \\ Regione Calabria, Italy
}

\begin{abstract}
Calabria Region supports the choices of cities in terms of urban mobility in an integrated approach by a high level of cooperation, coordination and consultation between the different levels of government and relevant authorities. Urban mobility includes city logistics. The Region supports all interventions according to European directions, as Sustainable Urban Mobility Plans, leaving from urban logistics topic. In particular, regional administration supports local administrations to realize an efficient urban logistic by the implementation of Regional Transport Plan Measure 2.5 City Logistics, in the general framework of urban planning. The aim is to improve sustainability and livability of cities pursuing national and international social, economic and environmental goals. Calabria Region have implemented a programming and execution process carried out by regional offices on city logistics. The programming process is finalized at Implementation Program definition and its approval by regional executive government. The Implementation Program indicates the city logistic measures and their realization procedures. The execution process is finalized at Call definition. The aim of Call is to finance design and realization of city logistic projects in all the cities of Calabria that satisfy some constraints. In this paper, programming and execution actions on city logistics of Calabria Region are presented.
\end{abstract}

Keywords: urban mobility, city logistics, planning, programming, execution.

\section{INTRODUCTION}

Urban areas account for a high share, some $23 \%$, of all $\mathrm{CO}_{2}$ emissions from transport. Cities need to make more efforts to turn past trends around and contribute to achieving the $60 \%$ reduction in greenhouse gas (GHG) emissions called for by the White Paper on transport [1].

In cities, it is complex to move towards a low-carbon transport than the transport system as a whole, but there is a greater potential of several measures such as walking, cycling, public transport and the early market introduction of vehicles powered by alternative fuels.

In urban mobility, the freight transport has negative externalities on sustainability development in environmental term, as well as on economic and social terms [2]-[4].

City logistics is an effective tool to reduce the impacts of freight transport by measures implementation [5]. There is a wide range of city logistics measures that can be grouped into different categories [6], [7]: supply management, demand management, infrastructural actions, ICT and ITS application, environment-friendly vehicle, support for public-private collaboration, reverse logistics.

Local administrations are called to city logistics implementation to achieve the wellness of citizens and the general liveability, without depressing economic and social vitality of urban areas and overcoming adversity of retailers and couriers.

Around the world, some large cities (London, Paris, Barcelona, and Rome) include city logistics within their urban transport plans [8]. Several small and medium-size cities faced with difficulties in addressing city logistics problems, and urban mobility in general. 
Looking at Sustainable Urban Mobility Plan (SUMP), local administration have difficulties to planning integrated solutions in urban mobility due to few knowledge and the lack of capability [9].

Calabria Region policies are oriented to supports local administrations in urban planning, including urban mobility and logistic, to promote the sustainability development in cities [10], [11].

Calabrian cities are small and medium-size, only in a few cases with more than 30,000 inhabitants; they are characterized by negative externalities because often they are without management of urban distribution of goods and they do not have sufficient structures and skills to develop city logistics planning.

After the approval of the Regional Transport Plan (RTP), the Region government has allocated financial resources to program Measure 2.5 City Logistics, which concerns the freight components of the urban mobility.

These financial resources allowed to move from planning to programming and then to the execution phases of projects.

\section{PLANNING PROCESS}

\subsection{European level}

In 2007, the Green Paper gave new impetus to the debate at the European level on urban mobility issues and the role of the EU in this area [12]. In 2009 an Action Plan on Urban Mobility (APUM) is adopted and provides a coherent framework for a set of concrete actions to be implemented by 2012 [13]; in 2013 is conducted a review of the APUM, following its implementation [14].

In 2011, the White Paper on transport defines a strategy by ten goals designed to guide policy actions and measure progress [15]. These ten goals are underpinned by 40 concrete initiatives for a resource-efficient Europe.

From White Paper and review of the implementation of the APUM, in 2013 European Commission developed Urban Mobility Package (UMP).

In Fig. 1 European main references on urban logistics schematically are represented.

UMP refers to initiatives 31,32 and 33 of the White Paper.

Initiative 31 called for establishing procedures and financial support mechanisms at the European level for preparing Urban Mobility Plans.

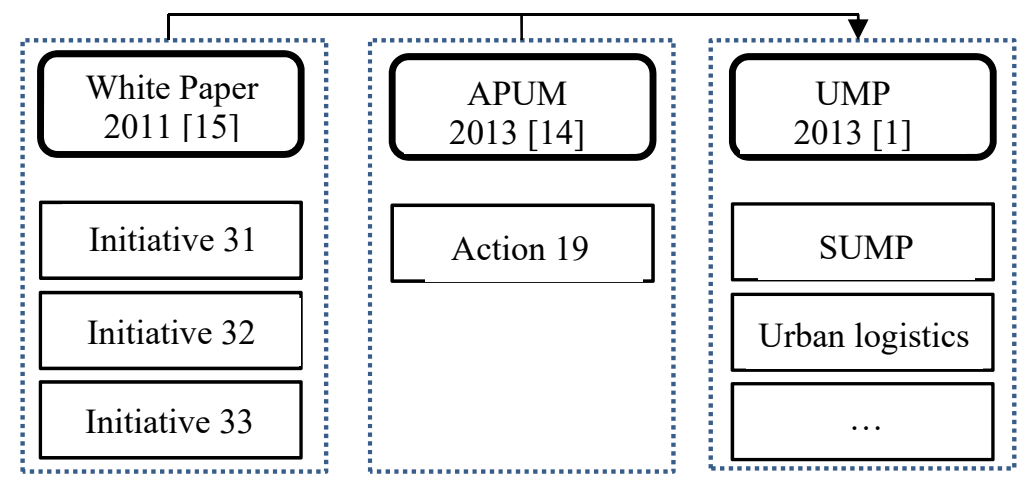

Figure 1: European main references on urban logistics. 
Initiative 32 foresaw the development of a package for urban road user charging and access restriction schemes;

Initiative 33 covered the production of best practice guidelines to better monitor and manage urban freight flows.

UMP European commission defines a several urban mobility actions [16]:

- Sustainable Urban Mobility Plans;

- public transport;

- urban logistics;

- green zones;

- alternative fuels.

\subsubsection{Sustainable Urban Mobility Plan}

Sustainable Urban Mobility Plan (SUMP) is the most important topic in the Commission's UMP and it has been promoted via the APUM [13], [14] and the White Paper on transport [15].

European Commission commissioned the guidelines Developing and Implementing a Sustainable Urban Mobility Plan. The guidelines are the result of a thorough and Europeanwide expert consultation process organised between 2010 and 2013 [17], [18].

The objective of guidelines is to accelerate the large-scale uptake of SUMP in Europe, as proposed in the APUM.

These guidelines are aimed at experts in urban transport and mobility and at other stakeholders who would be involved in the development and implementation of a SUMP.

A SUMP is a strategic plan designed to satisfy the mobility needs of people and businesses in cities and their surroundings for a better quality of life. It builds on existing planning practices and takes due consideration of integration, participation, and evaluation principles [18].

SUMP has as its central goal improving accessibility of urban areas and providing highquality and sustainable mobility and transport to, through and within the urban area. It regards the needs of the city and its hinterland rather than a municipal administrative region [18].

In contrast to traditional transport planning approaches, SUMP suggest as a new planning concept to solve problems of urban areas in a more sustainable and integrative way. The new concept of SUMP places particular emphasis on the involvement of citizens and stakeholders, the coordination of policies between sectors such as transport, land use, environment, economic development, social policy, health, safety and the coordination between authority levels and between neighbouring authorities.

A SUMP presents long-term strategy for the future development of the urban area respect to the development of transport and mobility infrastructure and services.

The topics addressed are:

- public transport;

- non-motorised transport;

- inter-modality;

- urban road safety;

- road transport;

- urban logistics;

- mobility management;

- intelligent transport systems. 
Respect to urban logistics, a SUMP should present measures to improve the efficiency of urban logistics, including urban freight delivery, while reducing related externalities like emissions of GHG, pollutants and noise [19].

\subsubsection{Urban logistics}

Urban logistics is also one of the focus topics in the Commission's UMP.

Urban logistics plays an important role in urban mobility because freight transportation is one of the main responsible of cities sustainability in terms of:

- economy, due to logistic costs and price of products [20];

- $\quad$ society, due to risk of accidents [21], [22];

- environment, due to congestion, air pollution, noise issues [23]-[25].

Then city logistics is essential for cities to function successfully [26], however they are often neglected in urban planning.

City logistics aims to reduce negative externalities associated to freight transportation in urban areas while supporting the sustainable development of the cities.

Then city logistics explicitly aims to optimize such advanced urban transportation systems and can contribute to create more efficient and environmentally friendly urban freight transport systems.

In urban planning, city logistics concerns planning of different measures, other than basic infrastructural measures, such as ITS, change in mind-sets of logistics managers, publicprivate partnerships can promote city logistics policy measures [27].

The European Commission has implemented a number of programs to boost jobs, growth and investment through the financial framework 2014-2020.

The Commission finances prototypal programs, it promotes the dissemination of best practice and it produce additional guidance documents. The aim is to facilitate the implementation of measures of urban logistics, such as delivery spaces, access regulations, and enforcement. These measures are functional to positive business for the private operators (retailers, shippers, carriers) and to increase of liveability for citizens.

Horizon 2020 and LIFE are the main funding opportunities available for urban mobility projects, which may include city logistics. Horizon 2020 calls for research and innovation projects of relevance to urban mobility include: Smart, green and integrated transport, Smart Cities and communities, Next-generation batteries, green vehicles and nature-based solutions. Horizon 2020 projects in urban mobility have been grouped under the CIVITAS initiative [28], [29].

LIFE is the EU's financial instrument for the environment, nature conservation and climate action. Under the theme of climate change mitigation, projects focusing on the efficient use of energy in the transport sector are supported [30].

Actually, there is not (clear) financial line in the regional funds for city logistics, neglecting SUMP policy.

\subsection{Regional level}

In 2016 Calabria Region approved RTP with a positive evaluation by the Regional Department of Environmental and Territorial Protection, and a positive evaluation by the EU Commission [31].

RTP supports Calabria Region policies in terms of transport and logistics, in the medium and long term.

RTP general vision is specified by four goals: 
- regional economic development;

- external accessibility;

- internal accessibility;

- sustainability.

To pursue this general vision RTP defines ten strategic objectives. To each objective corresponds a strategic action and to each strategic action corresponds ten operational measures. Then, RTP consists of ten actions for one hundred measures.

The Objective 10 Coordination planning monitoring and sharing indicates Action 10 Measures for planning, monitoring, participation and resources of the regional transport and logistics system. In this action there is a specific measure related to products of transport regional plan process: Measure 10.3 Products of the Process from the Director Plan. Among these products, Regional Government Decision and Implementation Program are defined as specific zoomed tools of RTP [32]:

- $\quad$ Delibera di Giunta Regionale, Regional Government Decision (DGR);

- Programma di attuazione, Implementation Program.

$D G R$ is the legal act imputed a regional executive government, consisting of a plurality of persons.

Implementation Program indicates the programmable measures that can be implemented in line with the RTP and EU planning documents and procedures.

The Objective 2 Urban areas indicates Action 2 Measures for infrastructure upgrading and services in urban areas. In this action there is a specific measure related to city logistics: Measure 2.5 City Logistics.

The Measure 2.5 specifies the interventions that can be implemented:

- $\quad$ regulation of the supply

o regulation with time windows,

o regulation of accesses with reference to the dimensions of freight vehicles,

o regulation of the use of preferential lanes for local public transport,

o regulation of accesses with an NDA network (nearby delivery area),

o integration with long-distance intermodal transport with UDC (urban distribution centre);

- $\quad$ demand management

o support to urban policies aimed at promoting innovative models based on cooperation between the actors involved, and the development of local public and private partnerships between the various actors,

o rationalization of distribution, with the maximization of loads per vehicle and the minimization of total vehicles;

- infrastructural interventions

o preparation of delivery area network (including booking) within LTZ,

o preparation of UDC and NDA,

o preparation of a pick-up point to support the new online purchase models (e-commerce); 
- $\quad$ ICT and ITS applications
o specific app or services on existing telematics networks,
o traffic management and control (including delivery area booking);

- $\quad$ use of eco-friendly and innovative vehicles

o upgrading of zero-impact vehicle fleets,

o regulation of accesses with environmental performance of freight vehicles;

- interventions for public-private collaboration

- analysis and control of all the components of urban logistics with attention to reverse logistics in all segments: from returns to other recovery phases.

The Region supports all interventions that are inspired and related to the actions identified in the APUM proposing twenty measures to encourage and help local, regional and national authorities in achieving their goals for sustainable urban mobility [13].

In particular Region supports all interventions that are inspired and related to action $19-$ Urban Freight Transport, both promoting the dissemination of information both with adequate incentive support for participation in all European tenders, and with specific supplementary contributions for municipalities that win national or supplementary European tenders, considering the priorities obtainable with the interventions envisaged by the ROP for efficiency improvement energy [13], [31].

The main mission of RTP, linked to a sustainability vision, is according to Transport White Paper: Achieve essentially $\mathrm{CO}_{2}$-free city logistics in major urban centres by 2030 [15].

\section{REGIONAL ACTIONS ON CITY LOGISTICS}

The urban mobility policies of the Oliverio's regional government are oriented to support local administration on the preparation of SUMPs. It need to consider the centrality of transport in the development of the city and its link with spatial and economic development [33]. For urban logistics SUMP's topic, regional administration supports local administrations to realize an efficient urban logistic by implementation of Measure 2.5 City Logistics. The idea is to support in doing the city. Then the Calabria Region don't finance the generic plan, even if prepared in the contest of actions of SUMP [34], but specific programming with the documents that defined them, if the generic city has specific strategic and tactical plan approved, as Limited Traffic Zone (ZTL).

With the approval of the RTP, the Region government has allocated financial resources to implement Measure 2.5 City Logistics to distribute to the cities of Calabria. These financial resources allowed to move from planning to programming and then to the execution of projects.

Below the financial resources to finance city logistics projects and the actions of the Region to programming and to execution are described.

\subsection{Action Plan for Cohesion}

The Action Plan for Cohesion (PAC) is a national strategic programming introduced in 2012, in agreement with the European Commission. The objective is to finance programs for territorial cohesion.

The final proposal of PAC 2014-2020, approved by regional government in 2016, provides 14 Axes. 
The Axis 7 Development of sustainable mobility networks has correlated Thematic Objective 7 Promote sustainable transport systems and eliminate bottlenecks in the main network infrastructures.

The Objective 7, 7.3 Improvement of regional mobility, modal integration and improvement of multimodal connections defines Action 7.3.3 Create intelligent info-mobility platforms and tools for monitoring and managing traffic flows of goods and people.

The Action 7.3.3 allows financing measures realization of urban logistics related to the APUM, in particular to Action 19 - Urban Freight Transport.

\subsection{Programming}

Programming process is finalized at Implementation Program on Measure 2.5 City logistics definition and his approval by DGR 391/2017.

The objectives of Implementation Program on Measure 2.5 City logistics are [32]:

- $\quad$ to specify RTP vision on city logistics;

- to reconstruct documentary framework of plans and projects in Europe, Italy and Calabria;

- to define
o city logistics area,
0 city requirements,
o fundable interventions,
o minimum level of project,
o operative period,
o costs;

- to indicate operational specifications to
o evaluation,
o financing.

The city logistics area is the area where the interventions will be made [35].

The city requirements to submit a financing proposal are:

- more than 30,000 inhabitants, or

- less than 30,000 inhabitants and operational Limited Traffic Zone (ZTL).

The fundable interventions can be implemented are one or more measure of Type 1 or 2, or a combination of Type 1 and 2 (Table 1).

The minimum level of project concerns time windows framework, which vary respect to vehicles, in terms of load, engine and environmental performance. The minimum level of time windows framework is different for projects with Type 1 or Type 1/2 measures.

The operative period is six years from starting; then cities to maintain the active measures fort this period is obliged.

The costs of financing are assigned according to city requirements and to the size of the city logistics area and the type of project.

The operational specifications for evaluation concerns the methodology to measure the results respect to:

- reduction of pollution, by size of the city logistics area, residents density, retailers density, other people over the residents, tourism; 
- increase in distribution efficiency, by shops, change in state current project in to freight flows, supply, environmental pollution and zero-impact vehicle fleets;

- $\quad$ sustainability of the project, by outcomes, monitoring, co-financing, participation events with stakeholders, integration with other sustainable mobility projects, governance.

Table 1: Fundable interventions.

\begin{tabular}{lcc}
\hline Interventions & Type 1 & Type 2 \\
\hline $\begin{array}{l}\text { a) Regulation of the supply } \\
\text { Regulation with time window }\end{array}$ & \\
$\begin{array}{l}\text { Regulation of accesses with reference to the dimensions of freight } \\
\text { vehicles }\end{array}$ & $\mathrm{X}$ \\
$\begin{array}{l}\text { Regulation of accesses with an NDA network } \\
\text { Integration with long-distance intermodal transport with UDC } \\
\text { b) Infrastructural interventions }\end{array}$ & $\mathrm{X}$ \\
$\begin{array}{l}\text { Preparation of delivery area network (including booking) within LTZ } \\
\text { Preparation of UDC and NDA }\end{array}$ & $\mathrm{X}$ \\
$\begin{array}{l}\text { Preparation of a Pick-up Point to support the new online purchase } \\
\text { models } \\
\text { c) ICT and ITS applications }\end{array}$ & $\mathrm{X}$ \\
$\begin{array}{l}\text { Specific app or services on existing telematics networks } \\
\text { Traffic management and control (including delivery area booking) } \\
\text { d) Use of eco-friendly and innovative vehicles }\end{array}$ & $\mathrm{X}$ \\
Upgrading of zero-impact vehicle fleets, & $\mathrm{X}$ \\
$\begin{array}{l}\text { Regulation of accesses with the environmental performance of freight } \\
\text { vehicles }\end{array}$ & \\
e) Reverse logistics & $\mathrm{X}$ \\
\hline
\end{tabular}

The operational specifications for financing concerns the methodology to assign the PAC resources, which provides that they be assigned by a Call.

Implementation Program is a result of participatory approach achieved with all stakeholders' involved in city logistics process, by public engagement form. The Region has developed workshops during which participants interacted on aspects of freight distribution sustainability. In the first workshop (June 2017) the focus has been on environnemental effects. In the second workshop (July 2017) the focus has been on economic and social effects.

Programming process concluded when regional government approved Implementation Program for the city logistics by DGR 391/2017 on 10 August 2017.

\subsection{Time windows constraints}

The time windows constraints vary respect to Type of project and for each type project respect to vehicles, in terms of load, engine and environmental performance also.

In Tables 2 and 3 time windows constraints are reported.

The classification of vehicles in terms of load is given according to Nuovo codice della strada [36], in terms of environmental performance is given according to European directives and regulations [37]. In particular, N-category vehicles are motor vehicles for transporting goods with at least 4 wheels; Lx category vehicles are vehicles with 2, 3 or 4 wheels. 
Table 2: Time windows constraints (Type 1).

\begin{tabular}{|c|c|c|c|c|}
\hline Vehicle & Load $(\mathrm{t})$ & Engine & Euro & Time windows \\
\hline $\mathrm{N} 1, \mathrm{~N} 2$ & $\leq 12$ & Combustion & $\begin{array}{l}\text { Pre-euro } \\
1,2,3,4,5,6\end{array}$ & 6 am-10 pm, $\max 3$ hours \\
\hline N3 & $>12$ & Combustion & $\begin{array}{l}\text { Pre-euro } \\
1,2,3,4,5,6\end{array}$ & $\begin{array}{c}10 \mathrm{pm}-6 \text { am } \\
\text { (with permission on path and time) }\end{array}$ \\
\hline Lx & & Combustion & $\begin{array}{l}\text { Pre-euro } \\
1,2,3,4,5,6\end{array}$ & 6 am-10 pm, max 4 hours \\
\hline
\end{tabular}

Table 3: Time windows constraints (Type 2 or $1+2$ ).

\begin{tabular}{|c|c|c|c|c|}
\hline Vehicle & $\operatorname{Load}(\mathrm{t})$ & Engine & Euro & Time windows \\
\hline All & All & Electric & & Up to $24 \mathrm{~h}$ \\
\hline N1, N2 & $\leq 12$ & Combustion & 6 & $\begin{array}{l}6 \text { am-10 pm, max } 3 \text { hours } \\
10 \text { pm-6 am, max } 4 \text { hours }\end{array}$ \\
\hline N1, N2 & $\leq 12$ & Combustion & $\begin{array}{l}\text { Pre-euro } \\
1,2,3,4,5\end{array}$ & $\begin{array}{l}10 \mathrm{pm}-6 \text { am } \\
\text { (with permission on path and time) }\end{array}$ \\
\hline N3 & $>12$ & Combustion & $\begin{array}{l}\text { Pre-euro } \\
1,2,3,4,5,6\end{array}$ & $\begin{array}{c}10 \mathrm{pm}-6 \mathrm{am} \\
\text { (with permission on path and time) }\end{array}$ \\
\hline $\mathrm{Lx}$ & & Combustion & $\begin{array}{c}\text { Pre-euro } \\
1,2,3,4,5,6\end{array}$ & none \\
\hline
\end{tabular}

\subsection{Execution}

Execution process is finalized at Call definition. The aim of Call is to finance design and realization of city logistics in all the cities of Calabria, subject to some constraints and performing higher target for outcomes and goals.

The Call has been defined according to Implementation Program and it is opened from September to November 2018 [38].

The Call indicates the criteria to projects evaluation respect to the results estimated by each proposal. The aim is to give a score to each proposal and to make a ranking to assign the financing. The maximum score is 100 obtained from the sum of reduction of pollution score (maximum 60), increase in distribution efficiency (maximum 20) and sustainability of the project (maximum 20).

Each city gave a self-assessment to its proposal. In fact the Call foresees that the proposal is accompanied by a form in which, based on the criteria, each city must score its own results.

There were 6 cities that submitted a financing proposal.

In December 2018, regional offices published eligible projects provisional list. This list is made based on the control of the documents requested by Call and sent to the regional offices. In this provisional list, there were 2 accepted cities.

In March 2019, regional offices published eligible projects final list. This list is made based on the legal recourse of some cities not accepted. In this final list, there were 4 accepted cities.

In May 2019, regional offices published city projects ranking. This ranking is made on methodology to evaluation defined in Implementation Program and on the criteria defined. In this ranking the evaluated cities were three, because one of the four present in the eligible 
projects final list has submitted a proposal that does not meet the technical requirements of the Call.

In Table 4 the time schedule is reported.

Table 4: Time schedule.

\begin{tabular}{|l|l|l|l|l|l|l|l|l|l|}
\hline Month/Year & $9 / 18$ & $10 / 18$ & $11 / 18$ & $12 / 18$ & $1 / 19$ & $2 / 19$ & $3 / 19$ & $4 / 19$ & $5 / 19$ \\
\hline Open all & & & & & & & & & \\
\hline $\begin{array}{l}\text { Administrative } \\
\text { preliminary activity }\end{array}$ & & & & & & & & & \\
\hline Provisional list & & & & & & & & & \\
\hline $\begin{array}{l}\text { Administrative } \\
\text { preliminary activity } \\
\text { - Legal recourse }\end{array}$ & & & & & & & & & \\
\hline Final list & & & & & & & & & \\
\hline $\begin{array}{l}\text { Administrative } \\
\text { evaluation activity }\end{array}$ & & & & & & & & & \\
\hline Ranking & & & & & & & & & \\
\hline
\end{tabular}

Financial resources PAC 2014-2020 were enough to finance all projects ranking.

Execution process is in progress. Formally, regional execution concluded when regional and local government sign the contract to regulate the transfer of funds, but really, the integrated approach between the different levels of government will continue in the implementation and executive phases of the city logistics projects managed by the city.

\section{CONCLUSION}

Calabria Region supports the choices of cities for sustainability in terms of urban mobility, including city logistics.

The Region push local administrations to realize an efficient urban logistic by implementation of RTP Measure 2.5 City Logistics, according to APUM and to SUMP.

City logistics aims to reduce negative externalities associated to freight transportation in urban areas while supporting the sustainable development of the cities.

Starting from RTP, Calabria Region has implemented a programming and execution process of city logistics carried out by regional offices leaving conclusion in May 2019 when regional offices published fundable projects ranking. Financial resources PAC 2014-2020 were enough to finance all projects verifying constraints in ranking.

In less than a year from call publication, the Region allowed to cities to optimize freight component of the urban mobility, looking to SUMP preparation.

On this result, the Region is working to develop another Call to finance the realization of other projects.

\section{REFERENCES}

[1] European Commission, Together towards competitive and resource-efficient urban mobility, 17.12.2013 COM(2013) 913 final, European Commission: Brussels, 2013.

[2] Browne, M., Allen, J. \& Alexander, P., Business improvement districts in urban freight sustainability initiatives: A case study approach. Transportation Research Procedia, 12, pp. 450-460, 2015. 
[3] Taniguchi, E., City logistics for sustainable and liveable cities. Green Logistics and Transportation: A Sustainable Supply Chain Perspective, eds B. Fahimia, M.G.H. Bell, D.A. Hensher, \& J. Sarkis, Springer: Cham, Switzerland, pp. 49-60, 2015.

[4] Taniguchi, E. \& Thompson, R. (eds), City Logistics 3: Towards Sustainable and Liveable Cities, Wiley, 2018.

[5] Russo, F., Modelling behavioral aspects of urban freight movement. Freight Transport Modelling, eds M. Ben-Akiva, H. Meersman \& E. Van de Voorde, Emerald Group: Bingley, UK, 2013.

[6] BESTUFS, BESTUFS: Good practice guide on urban freight, 2007. www.bestufs.net.

[7] Russo, F. \& Comi, A., A classification of city logistics measures and connected impacts. Procedia - Social and Behavioral Sciences, 2(3), pp. 6355-6365, 2010.

DOI: $10.1016 /$ j.sbspro.2010.04.044.

[8] Nuzzolo, A., Comi, A., Ibeas, A. \& Moura, J.L., Urban freight transport and city logistics policies: Indications from Rome, Barcelona and Santander. International Journal of Sustainable Transportation, 10(6), pp. 552-566, 2016.

DOI: 10.1080/15568318.2015.1014778.

[9] Russo, F., Panuccio, P. \& Rindone, C., European plans for smart city: From theories and rules to logistics test case. European Planning Studies, 2016.

DOI: $10.1080 / 09654313.2016 .1182120$.

[10] Hall, P.G., Urban and Regional Planning, 4th ed., Routledge: London, 2002.

[11] Healey, P. \& Williams R., European urban planning systems: Diversity and convergence. Urban Studies, 30(4/5), pp. 701-720, 1993.

[12] European Commission, Green paper, Towards a new culture for urban mobility, $\operatorname{COM}(2007) 551$ final, 2007. https://eur-lex.europa.eu/legal.

[13] European Commission, Action plan on urban mobility, $\operatorname{COM}(2009)$ 490, 2009. https://ec.europa.eu/transport/themes/urban/urban_mobility/action_plan_en.

[14] European Commission, Review of the action plan on urban mobility. Panteia, Research to progress, 2013. https://ec.europa.eu/transport/sites/transport/files/themes/urban/ studies/doc/2013-07-review-of-the-action-plan-on-urban-mobility.pdf.

[15] European Commission, White paper 2011, Roadmap to a single European transport area: Towards a competitive and resource efficient transport system, COM(2011) 144 final, 2011.

[16] European Commission, Mobility and transport, Clean transport, Urban transport, Urban mobility actions (last update, July 2019). https://ec.europa.eu/transport/themes/ urban/urban_mobility/urban_mobility_actions_en.

[17] European Commission, Sustainable urban mobility plans, 2013. https://ec.europa.eu/ transport/themes/urban/urban_mobility/urban_mobility_actions/sump_en.

[18] European Commission, Guidelines developing and implementing a sustainable urban mobility plan, 2013. www.eltis.org/guidelines/sump-guidelines.

[19] European Commission, Together towards competitive and resource-efficient urban mobility, $\operatorname{COM(2013)~} 913$ final, Annex 1, 2013. https://ec.europa.eu/transport/sites/ transport/files/themes/urban/doc/ump/com\%282013\%29913-annex_en.pdf.

[20] Taniguchi, E., Fwa, T.F. \& Thompson, R.G., Urban Transportation and Logistics: Health, Safety, and Security Concerns, CRC Press: Baca Raton, 2013.

[21] Elvik, R., Vaa, T., Erke, A. \& Sorensen, M., The Handbook of Road Safety Measures, Emerald Group: Bingley, UK, 2009.

[22] Russo, F. \& Comi, A., From the analysis of European accident data to safety assessment for planning: The role of good vehicles in urban area. European Transport Research Review, 9(9), pp. 1-12, 2017. DOI 10.1007/s12544-017-0225-0. 
[23] Waygood, E.O.D., Chatterton, T. \& Avineri, E., Comparing and presenting city-level transportation $\mathrm{CO}_{2}$ emissions using GIS. Transportation Research Part D, 24, pp. 127-134, 2013.

[24] Taniguchi, E., Concepts of city logistics for sustainable and liveable cities. Procedia Social and Behavioral Sciences, 151(2014), pp. 310-317, 2014.

[25] Russo, F. \& Comi, A., Urban freight transport planning towards green goals: Synthetic environmental evidence from tested results. Sustainability, 8(4), p. 381, 2016. DOI: $10.3390 /$ su8040381.

[26] Taniguchi, E. \& van der Heijden, R.E.C.M., An evaluation methodology for city logistics. Transport Reviews, 20(1), pp. 65-90, 2000.

[27] Musolino, G., Rindone, C. \& Vitetta A., Passengers and freight mobility with electric vehicles: A methodology to plan green transport and logistic services near port areas. Transportation Research Procedia, 37, pp. 8-393, 2019.

[28] European Commission, Horizon 2020, 2019. https://ec.europa.eu/programmes/horizon2020/en.

[29] van Rooijen, T. \& Quak, H., City logistics in the European CIVITAS initiative. Procedia Social and Behavioral Sciences, 125, pp. 312-325, 2014.

DOI: 10.1016/j.sbspro.2014.01.1476.

[30] European Commission, LIFE, 2019. https://ec.europa.eu/easme/en/life.

[31] Calabria Region, Regional transport plan, 2016. http://portale.regione.calabria.it/ website/organizzazione/dipartimento6/subsite/pianoregionale/.

[32] Calabria Region, Regional Government Decision (DGR 391/2017), Implementation Program, 2017.

[33] Russo, F. \& Musolino, G., A unifying modelling framework to simulate the spatial economic transport interaction process at urban and national scales. Journal of Transport Geography, 24, pp. 189-197, 2012.

[34] Italy Ministry of Infrastructure and Transport, Individuazione delle linee guida per i piani urbani di mobilita' sostenibile, ai sensi dell'articolo 3, comma 7, del decreto legislativo 16 dicembre 2016, n. 257, 2017. www.gazzettaufficiale.it/eli/id/2017/10/ 05/17A06675/sg.

[35] Russo, F. \& Comi, A., From city logistics theories to city logistics planning. City Logistics 3 - Towards Sustainability and Liveable Cities, eds E. Taniguchi \& R.G. Thompson, Wiley: London, pp. 329-348, 2018.

[36] Italy, Nuovo codice della strada, Decreto legislativo 30 aprile 1992 n. 285, 1992. www.aci.it/i-servizi/normative/codice-della-strada/titolo-iii-dei-veicoli/art-47classificazione-dei-veicoli.html.

[37] EU, Cars and light trucks (last update July 2019). www.dieselnet.com/standards/eu/ld.php\#stds.

[38] Calabria Region, Manifestazione di interesse, 2018. http://portale.regione.calabria.it/ website/portaltemplates/view/view_bando.cfm?2279. 